\title{
Derivation and Correlation of Human Involvement in Assessment of Demand Scheduling in the Process of Logistics Improvement in an Oil Refinery
}

\author{
Pankaj Mohan Prasad ${ }^{1}$, S.K.Pokhriyal(PhD) ${ }^{2}$ \\ ${ }^{1}$ Assistant Professor, Oil and Gas Deptt, UPES, Dehradun \\ ${ }^{2}$ Professor and Head of Oil and Gas and ET, UPES, Dehradun \\ pmprasad@ddn.upes.ac.in
}

\begin{abstract}
The paper is an exploration of a novel concept to reduce the mechanistic dependency of the Human(Personnel)involved in the routine jobs of refinery demand assessment and scheduling operations. It highlights the importance of scheduling and the factors for an optimal job.

The paper identifies and incorporates the Human Factors and derives a mechanism in a model based analysis to understand and optimize the productivity output, in the scheduling operations, and better and efficient way of achieving company objectives.
\end{abstract}

Keywords: Supply, demand, humans, productivity.

\section{INTRODUCTION}

This paper examines the factors leading to supply chain efficiency and proper management leading to margin and profitability improvement in oil and gas industry, with particular emphasis on the scheduling process.

This is a conceptual approach in identifying what is in a simplified form a novel development in assessing and evaluating the supply margin linkage.

On a broader terms the factors driving logistics plan depends on the following factors

1.The proper scheduling of the material

2. Proper communication

3. Right tools for schedule the supply and delivery process.

4. Choice of the right vendor

5. Flow of information smoothly

6. A perfect coordination among the personnel involved

7. A verification system to eradicate errors and minimize costs and losses

Scheduling is generally understood to be fulfilling the demand supply requirements in an organized way throughout the organization and is further classified unitwise, productwise, quality wise, price wise etc.

What is new in this paper is the development of a concept in which a method of rationalization of the demand assessment of the product material is made. 
It highlights the importance of the training need and compliance of the personnel involved, in procurement process of the material, also stressing the need for training programs to specifically train the people in the need be so.

\section{Assessment is a critical factor because}

1. Proper assessment links to entire manufacturing cycle. It attaches the importance of knowledge connected with

a. company profile

b. process flow

c. Product info

d. quality concern

e. cost savings

f. profit margins

2. Knowledge based and educated assessment process is always better and recommended over uneducated guesswork relying on chance and trial.

This is important to best judge the suitability of the person for the job

a. Erroneous estimation leads to inventory build up leading to carrying costs and increased expenses

b. Underestimation leads to frequent order placements and thereby more costs

c. Improper communication leads to spoilt relation with the vendor and an image distortion in the market and consequently affects the image and brand name of the company

\section{Another factor that affects the schedule and assessment process is the: Type of Organization}

The type of the organization in the subject concerned is also an important point to be kept in mind. Companies are also Standards related conforming to given norms to have an authorized certification of meeting the market challenges and be of competitive and quality standards to fulfill the consumer bases legally and justifiably.

4. Threats: Organizations always have to be on their toes to meet the threats on various counts. Threats increase the liability of the organization and increase the chances of liquidation and business shut down and closures.

These threats arise on the grounds of

a. Unsuitable personnel

b. Poorly trained staff

c. Inefficiencies

d. Quality failures

e. Carelessness and negligence

The paper focusses on how demand assessment is linked to Human factor $(\mathrm{H})$ in making effective scheduling programs

Volume 2016

Page 2 


\section{THE HUMAN FACTORS ARE}

\section{The capacity to make effective decisions. These depend upon}

a. Education and knowledge of the job and on educational qualification. The motivation to repeat the job and enthuse others for regularly good results

b. The realization of accountability or fear of being punished

c. Self development awareness and career growth ambitions for effective contribution to company goals

\section{A CONCEPTUAL MODEL}

\section{The Human Factor Analysis}

The three factors involved in the demand assessment for scheduling operations involve the

1. Material

2. Machine

3. Man(Human)

The factors can be symbolized by $\mathrm{M}^{3}$.

The M3 is further classified into

1. $\mathrm{M}^{3}\left(\mathrm{H}^{+}\right)$: This denotes high Human involvement

2. $\mathrm{M}^{3}\left(\mathrm{H}^{-}\right)$: This denotes low Human involvement

The Demand Assessment calls for Human Involvement depending on the system in use

For example: An oil refinery industry / refinery for example would be characterized by unit wide dependency of the Human Factor

1. A Hydrocracking unit or a conversion unit might use a conversion factor as high as $30 \%$ as a Relativity Factor Association (RFA) with the next or previous units.

2. The next step would be to highlight the Human Involvement Factor $(\mathrm{H})$ and RFA to draw maximum productivity in the refinery

3. The RFA is gauged considering the OBSERVED input / output traits over a time period on a percentage factor basis.

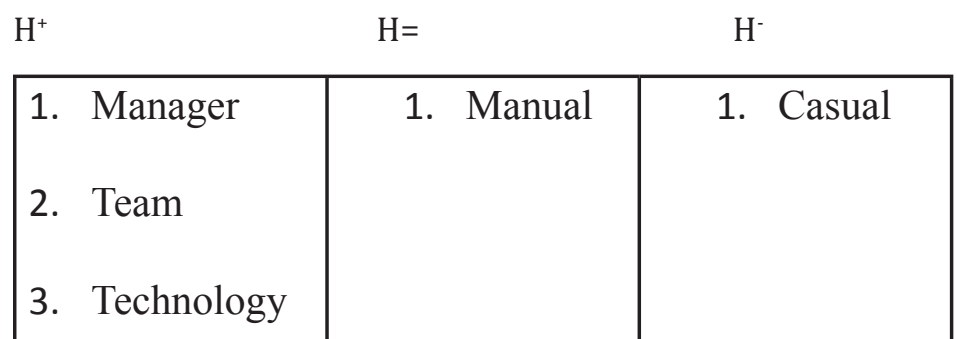

The above depiction explains different kinds of $\mathrm{H}+$ factor , priority-wise , say, for example in an oil refinery

1. $\mathrm{H}^{+}$connotation is for High involvement for a manager(productivity)

2. $\mathrm{H}^{=}$connotes medium involvement(Neutrality)

3. $\mathrm{H}^{-}$connotes a low involvement(liability)

Volume 2016 
The permutation-combination linkage between Human Factor $(\mathrm{H})$ and the RFA is given by the universal formula

$$
{ }^{\mathrm{n}} \mathrm{C}_{\mathrm{r}} \mathrm{p}^{\mathrm{r}} \mathrm{q}^{\mathrm{n}-\mathrm{r}}
$$

Where $\mathrm{n}=$ the number of cases

$r=$ the number of number team member in a group

$\mathrm{p}=$ probability of success

$\mathrm{q}=$ probability of failure

Where ${ }^{\mathrm{n}} \mathrm{C}_{\mathrm{r}}=\quad-\mathrm{n}$ !

The next objective is to rationalize the $\mathrm{H}$ factor maximized for $\mathrm{H}$ in $\mathrm{H}$ and RFA correlation using the weighted average mechanism

The formula derived will be

PA (Minus-F): $=\mathrm{H}^{+}\left(\mathrm{RFA}_{1}\right)+\mathrm{H}^{=}\left(\mathrm{RFA}_{2}\right)+\mathrm{H}^{-}\left(\mathrm{RFA}_{3}\right) \ldots \mathrm{H}^{\mathrm{n}}\left(\mathrm{RFA}_{\mathrm{n}}\right)$

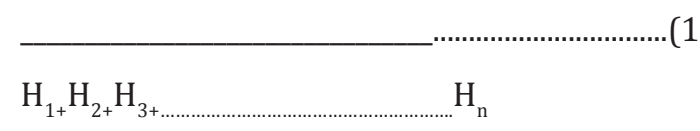

There are factors not directly connected but associated, they are explained by

1. Interest

2. Dedication

3. Motivation

4. Knowledge...etc

They can be clubbed together as a number/ integer ranked on scale convenient and added to The equation 1.

And denoted as PA(Plus F)

So to get the overall value of the indicator of Human Factor, we take the simple average of

$\mathrm{PA}_{\mathrm{av}}=\mathrm{PA}($ minusF $)+\mathrm{PA}(\mathrm{Plus} \mathrm{F})$

2

The $\mathrm{H}$ factor can be further refined to be operated under constraints:

$\mathrm{H}^{* *}$ to be a targeted

$\mathrm{H}^{*}$ to be constrained

Together they can be termed as Contributory Factor

Volume 2016 
Nearness Factor can be scaled to denote each Human Involvement divided by his or her contributory factor

$\mathrm{NF}_{1}=$ Indicates high involvement , better contribution and good estimation characteristics

$\mathrm{NF}_{2}=$ Indicates improvement necessary

$\mathrm{NF}_{3}=$ lower still involvement

These can be computed till ...n

Thus each Human Factor is characterized and denoted by his or hers effectiveness. Assessing these sums up all the factors and for the most optimal human involvement and results.

\section{CONCLUSION}

It is always pertinent to incorporate the Humans as an integral part of decision making at all levels, and the capabilities can be as this paper highlights, should be involved for a better output and increased productivity, in the organizations.

\section{REFERENCES}

1. State of Logistics Report, Council for Logistics Management, 2004.

2. Stewart, G.B., The Quest for Value, Harper Business, 1991 (EVA is a registered trademark of Stern Stewart \& Co).

3. Buffet, W., Annual Report, Berkshire Hathaway Corporation, 1994.

4. Srivastava, R. et al., 'Market-Based Assets and Shareholder Value: A Framework for Analysis', Journal of Marketing, Vol. 62, No. 1, January 1998, pp. 2-18.

6. Johnson, H.T. and Kaplan, R.S., Relevance Lost: The Rise and Fall of Management Accounting, Harvard Business School Press, 1987.

7. Barrett, T., 'Mission Costing: A New Approach to Logistics Analysis' International Journal of Physical Distribution and Materials Management, Vol 12, No. 7, 1982.

8. Shillinglow, G., 'The Concept of Attributable Cost', Journal of Accountin Research, Vol. 1, No. 1, Spring 1963.

9. Cooper, R. and Kaplan, R.S., 'Profit Priorities from Activity-Based Costing' Harvard Business Review, May-June 1991.

Citation: Pankaj Mohan Prasad ${ }^{1}$,S.K.Pokhriyal(PhD) ${ }^{2}$, Derivation and Correlation of Human Involvement in Assessment of Demand Scheduling in the Process of Logistics Improvement in an Oil Refinery. ARJBM Volume 2016; pp:1-5

Copyright (c) 2016 Pankaj Mohan Prasad', S.K.Pokhriyal(PhD)², This is an open access article distributed under the Creative Commons Attribution License, which permits unrestricted use, distribution, and reproduction in any medium, provided the original work is properly cited. 